\title{
Enhancement of Cellular Adenosine Triphosphate Levels in PC12 Cells by 2,5-Dideoxyadenosine, a P-Site Inhibitor of Adenylate Cyclase
}

\author{
Hiroyuki FuJIMORI* and Hidemitsu Pan-Hou \\ Faculty of Pharmaceutical Sciences, Setsunan University; 45-1 Nagaotoge-cho, Hirakata, Osaka 573-0101, Japan. \\ Received August 5, 2004; accepted November 15, 2004
}

\begin{abstract}
To elucidate the biological significance of the P-site inhibitor of adenylate cyclase, the effect of 2,5dideoxyadenosine (DDA) on cellular levels of adenine compounds in PC12 cells was studied. The addition of DDA and deoxyadenosine (deoxyAdo), P-site inhibitors of adenylate cyclase, as well as the addition of adenosine (Ado) to the incubation medium containing glucose as the sole nutrient significantly enhanced cellular ATP levels in PC12 cells. $N^{6}$-Methyladenosine and $N^{6}$-cyclohexyladenosine did not augment the ATP levels. The ATP level-enhancing effect of DDA was further enhanced by Ado. After pretreatment of PC12 cells with theophylline, DDAinduced ATP enhancement was potentiated by theophylline but the effect of Ado was suppressed. cAMP levels in PC12 cells were markedly reduced by DDA but the levels were not changed by Ado. These results suggest for the first time that P-site inhibitors of adenylate cyclase may stimulate ATP synthesis via glycolysis by decreasing cAMP levels and the mode of action of the ATP level-enhancing effect of DDA may be different from that of Ado.
\end{abstract}

Key words 2,5-dideoxyadenosine; P-site inhibitor; adenosine; PC12 cell; ATP synthesis

Extracellular adenosine (Ado) functions as intercellular signaling molecule by interacting with specific $\mathrm{P} 1$ receptors via G-proteins. ${ }^{1,2)}$ High concentrations of Ado are also known to inhibit adenylate cyclase directly via its P-site, which requires an intact purine base for activation. ${ }^{3)}$ However, the biological significance of inhibition of adenylate cyclase via the P-site remains to be elucidated.

Recently, Fujimori et al. ${ }^{4)}$ reported that extracellular Ado enhances cellular ATP levels in PC12 cells, a neuronal model, and speculated that the Ado-evoked ATP level enhancement might result in stimulation of ATP synthesis through a salvage pathway requiring hypoxanthine-guanine phosphoribosyltransferase (HGPT). Changes in cellular levels of cAMP released by adenylate cyclase are known to involve cellular glucose metabolism. ${ }^{5,6)}$ As P-site inhibitors of adenylate cyclase may regulate cAMP production in cells, it is of interest to know whether P-site inhibitors such as membrane-permeable ${ }^{7)}$ deoxyadenosine (deoxyAdo) and 2,5dideoxyadenosine (DDA) would influence on cellular ATP synthesis in PC12 cells.

In this study, we examined the effects of extracellular Adorelated compounds on cellular levels of adenine compounds, especially ATP, in PC12 cells. We report that extracellular DDA, a P-site inhibitor of adenylate cyclase, enhances the cellular ATP contents by a mechanism different from that of the ATP level-enhancing effect of Ado.

\section{MATERIALS AND METHODS}

Materials DDA, $N^{6}$-methyladenosine (methylAdo), and $N^{6}$-cyclohexyladenosine (cyclohexylAdo) were purchased from Sigma Chemical (St. Louis, MO, U.S.A.). DeoxyAdo, Ado, cAMP, adenosine 5-monophosphate (AMP), adenosine 5-diphosphate (ADP), and ATP were obtained from Yamasa Shouyu (Chiba, Japan). Theophylline and chloroacetaldehyde were from Wako Pure Chemicals (Japan). Fetal calf serum and inactivated horse serum were from IS Japan (Japan) and Gibco BRL (U.S.A.), respectively. Other chemicals of reagent grade were obtained commercially.

Cell Culture Rat pheochromocytoma PC12 cells were kindly supplied by Prof. K. Miura (Wako University, Tokyo, Japan). Cells were grown at $37^{\circ} \mathrm{C}$ in Dulbecco's modified Eagle's medium supplemented with $10 \%$ fetal calf serum, $5 \%$ heat-inactivated horse serum, glutamine $30 \mu \mathrm{g} / \mathrm{ml}$, and kanamycin $60 \mu \mathrm{g} / \mathrm{ml}$ in a humidified $7.5 \% \mathrm{CO}_{2}$ atmosphere.

Determination of Cellular Adenine Compounds in PC12 Cells Determination of cellular adenine compounds in PC12 cells was performed according to the method described previously. ${ }^{4)}$ In brief, PC12 cells were seeded in $35-$ $\mathrm{mm}$ Petri dishes at approximately $2 \times 10^{6}$ cells and cultured for $3 \mathrm{~d}$. PC12 cells were incubated with $1.5 \mathrm{ml}$ of $100 \mu \mathrm{M}$ adenine-related compound in Locke's solution $\{5.6 \mathrm{~mm}$ glucose, $154 \mathrm{~mm} \mathrm{NaCl}, 5.6 \mathrm{~mm} \mathrm{KCl}, 3.6 \mathrm{~mm} \mathrm{NaHCO}_{3}$, $5 \mathrm{~mm}$ 2-[4-(2-hydroyethyl)-1-piperazinyl]-ethanesulfonic acid (Hepes), $\mathrm{pH} 7.3\}$ at $37^{\circ} \mathrm{C}$ for $2 \mathrm{~h}$. After washing twice with Locke's solution, the cells were homogenized in perchloric acid. The perchloric acid-soluble compounds extracted from PC12 cells were treated at $85^{\circ} \mathrm{C}$ for $15 \mathrm{~min}$ with chloroacetaldehyde for fluorescence derivatization as described previously. ${ }^{8)}$ The derivatized compounds were analyzed with an HPLC system using a column of Hitachi gel No. 3013-N $(5 \mu \mathrm{m})$ as an anion exchanger. ${ }^{9)}$ The detection limit was $c a$. $1 \mathrm{pmol}$ in $10 \mu \mathrm{l}$ of the derivatized sample injected into our HPLC system.

Statistical Analysis All data are expressed as mean \pm S.E.M. Statistical evaluation of the data was performed using Student's $t$-test. $p$ values of $<0.05$ were considered to be significant.

\section{RESULTS}

As previously reported ${ }^{4}$ the addition of Ado, deoxyAdo, or DDA at a concentration of $100 \mu \mathrm{m}$ to the incubation medium significantly enhanced the individual cellular levels of ATP, ADP, and AMP (Table 1). MethylAdo and cyclohexylAdo had no effect on ATP levels in PC12 cells. DDA, a representative P-site inhibitor of adenylate cyclase, enhanced cellular ATP levels in a dose-dependent manner (Fig. 1). When coincubated with Ado $100 \mu \mathrm{M}$, the cellular ATP levels were further enhanced as compared with the levels induced 
Table 1. Effects of Various Adenine-Related Compounds on Cellular Adenine Compound Levels in PC12 Cells

\begin{tabular}{lllll}
\hline \hline & & \multicolumn{3}{c}{$\mathrm{nmol} /$ plate } \\
\cline { 2 - 5 } Addition $(100 \mu \mathrm{M})$ & AMP & cAMP & ADP & ATP \\
\hline None & $0.57 \pm 0.09$ & $0.36 \pm 0.02$ & $2.70 \pm 0.17$ & $18.93 \pm 1.23$ \\
Ado & $1.11 \pm 0.07^{*}$ & $0.38 \pm 0.03$ & $4.67 \pm 0.25^{*}$ & $32.42 \pm 1.84^{*}$ \\
DeoxyAdo & $1.22 \pm 0.09^{*}$ & $0.21 \pm 0.02^{*}$ & $5.02 \pm 0.27^{*}$ & $34.62 \pm 2.34^{*}$ \\
DDA & $1.12 \pm 0.09^{* *}$ & $0.01 \pm 0.00$ & $4.49 \pm 0.23^{*}$ & $31.87 \pm 2.13^{*}$ \\
MethylAdo & $0.82 \pm 0.13$ & $0.26 \pm 0.03^{* *}$ & $3.16 \pm 0.20$ & $20.86 \pm 1.11$ \\
CyclohexylAdo & $0.71 \pm 0.11$ & $0.32 \pm 0.03$ & $2.75 \pm 0.19$ & $18.49 \pm 1.20$ \\
\hline
\end{tabular}

Data are presented as mean \pm S.E.M. of three determinations. Data are representative of three independent experiments. $* p<0.01 v s$. none, $* * p<0.05 v s$. none.

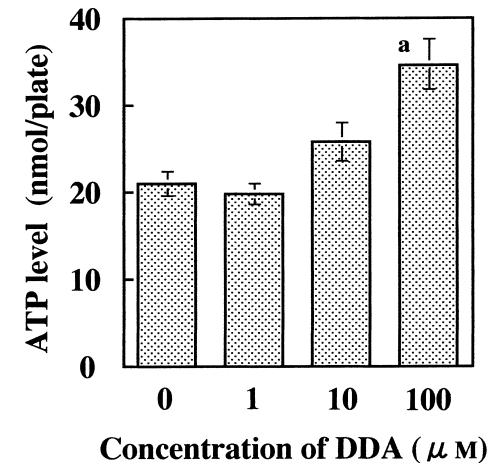

Fig. 1. Effect of Various Concentrations of 2,5-Dideoxyadenosine on Cellular ATP Levels in PC12 Cells

PC12 cells were incubated for $2 \mathrm{~h}$ with DDA. Data are expressed as mean \pm S.E.M. of three determinations. a) $p<0.01 v s$. control.

by DDA alone (Table 2). DDA markedly reduced cellular cAMP levels in PC12 cells, but Ado had no effect on the cAMP levels. DDA also suppressed cAMP levels in PC12 cells when coincubated with Ado (Table 2).

When PC12 cells were preincubated with theophylline $100 \mu \mathrm{M}$ for $20 \mathrm{~min}, \mathrm{DDA}$-induced ATP enhancement was further increased by theophylline (Table 3). However, Adoevoked ATP enhancement was significantly suppressed when coincubated with theophylline. Theophylline did not enhance cAMP levels in PC12 cells after 2-h incubation (Table 3).

\section{DISCUSSION}

Recently, the enhancement of cellular ATP levels in PC12 cells by extracellular Ado was proposed to be mediated by the salvage pathway through HGPT but not by the P1 receptor-mediated signaling pathway. ${ }^{4}$ Ribose-modified analogues of Ado such as DDA and deoxyAdo were found to increase cellular ATP levels (Tables 1-3). However, adenine ringmodified analogues of Ado such as methylAdo and cyclohexylAdo had no effect on ATP levels in PC12 cells (Table 1). These results are agreement with the previous results that various P1 receptor agonists, Ado analogues with chemical modification of adenine ring, did not affect cellular ATP levels. ${ }^{4)}$ DDA and deoxyAdo are neither proper substrates of HGPT for the synthesis of adenine nucleotides nor precursors of ATP because of the lack of a hydroxyl group at positions 2 and 5. The addition of Ado was found to enhance additionally the DDA-induced cellular ATP levels (Table 2). These results suggested that the mechanism of enhancing cellular ATP levels of DDA and deoxyAdo may be different
Table 2. Effects of Adenosine and 2,5-Dideoxyadenosine on the Levels of ATP and cAMP in PC12 Cells

\begin{tabular}{llr}
\hline \hline \multirow{2}{*}{ Addition } & \multicolumn{2}{c}{ nmol/plate } \\
\cline { 2 - 3 } & \multicolumn{1}{c}{ ATP } & \multicolumn{1}{c}{ cAMP } \\
\hline None & $22.98 \pm 1.48$ & $0.45 \pm 0.03$ \\
Ado $(100 \mu \mathrm{M})$ & $34.68 \pm 1.82^{*}$ & $0.43 \pm 0.02$ \\
DDA $(100 \mu \mathrm{M})$ & $32.66 \pm 1.63^{*}$ & $\left.0.00^{a}\right) \pm 0.00$ \\
Ado + DDA & $44.54 \pm 2.35^{* * * *}$ & $0.00^{a} \pm 0.01$ \\
\hline
\end{tabular}

Data are expressed as mean \pm S.E.M. of three determinations. a) Less than detection limit. $* p<0.05 v s$. none, $* * p<0.05 v s$. Ado or DDA.

Table 3. Effects of Theophylline on cAMP Levels and Adenosine- and 2,5-Dideoxyadenosine-Enhanced ATP Levels in PC12 Cells

\begin{tabular}{|c|c|c|}
\hline \multirow{2}{*}{ Addition } & \multicolumn{2}{|c|}{$\mathrm{nmol} / \mathrm{plate}$} \\
\hline & ATP & cAMP \\
\hline None & $20.82 \pm 1.34$ & $0.40 \pm 0.03^{\dagger}$ \\
\hline Ado $(100 \mu \mathrm{M})$ & $36.88 \pm 2.88^{*}$ & $0.44 \pm 0.03^{\dagger}$ \\
\hline $\operatorname{DDA}(100 \mu \mathrm{M})$ & $34.30 \pm 2.85 *$ & $0.00^{a} \pm 0.00$ \\
\hline Theophylline $(100 \mu \mathrm{M})$ & $23.98 \pm 1.69$ & $0.21 \pm 0.01$ \\
\hline Theophylline + Ado & $26.36 \pm 1.93^{* * * *}$ & $0.35 \pm 0.03 * * *$ \\
\hline Theophylline +DDA & $44.41 \pm 2.50 *, \dagger$ & $0.00^{a)} \pm 0.00$ \\
\hline
\end{tabular}

PC12 cells were preincubated with theophylline $(100 \mu \mathrm{M})$ in Locke's solution for $20 \mathrm{~min}$. After removal of theophylline, $100 \mu \mathrm{M}$ of each compound was added to PC12 cells. a) Less than detection limit. $* p<0.05 v s$. none; $* * p<0.05 v$ s. Ado; $* * * p<0.05$ $v s$. theophylline; ${ }^{\dagger} p<0.01 v s$. theophylline.

from that of Ado via the Ado salvage system requiring HGPT.

Theophylline is known to be a nonspecific antagonist of P1 receptors, ${ }^{1,2)}$ and inhibitor of cyclic nucleotide phosphodiesterase, ${ }^{2,10)}$ 5-nucleotidase, ${ }^{11,12)}$ and alkaline phosphatase, ${ }^{13)}$ and a weak inhibitor of HGPT. ${ }^{14,15)}$ As previously reported, ${ }^{4)}$ theophylline had no effect on the Ado-induced ATP levels in PC12 cells without pretreatment. On the contrary, pretreatment of PC12 cells with theophylline suppressed the Ado-induced ATP-enhancing effect, suggesting that theophylline might inhibit HGPT activity to produce ATP through Ado. Theophylline had no effect on P-site inhibition of adenylate cyclase in intact cells ${ }^{16)}$ and cell membrane. ${ }^{17)}$ The further increase in DDA-induced ATP enhancement with theophylline pretreatment (Table 3) suggests that theophylline may suppress cellular alkaline phosphatase, which is involved in the degradation of ATP into ADP, AMP, and Ado.

Glucose metabolism, especially glycolysis, in tissues are well regulated by intracellular changes in various adenine 
compound levels. ${ }^{18-20)}$ 6-Phosphofructokinase and pyruvate kinase, rate-limiting enzymes of glycolysis, are known to be activated by decreasing cellular cAMP levels. ${ }^{5,6)}$ When PC12 cells were incubated in Locke's solution containing glucose as the sole nutrient, the further increase in Ado-induced ATP enhancement by DDA was accompanied by a marked reduction in cellular cAMP levels (Tables 2, 3). To our knowledge, these results demonstrate for the first time that enhancement of cellular ATP levels in PC12 cells by the P-site inhibitor of adenylate cyclase is due to stimulation of ATP synthesis via glycolysis regulated by changes in cAMP levels in PC12 cells.

In general, adenosine 3-monophosphate (3-AMP) and deoxyadenosine 3-monophosphate (deoxyAMP), which are degradation products of RNA and DNA, respectively, are classified as representative naturally occurring P-site inhibitors. ${ }^{3)}$ Extracellular 3-AMP as well as adenosine 5monophosphate, adenosine 5-diphosphate and $\mathrm{ATP}^{4)}$ had no effect on cellular ATP levels in PC12 cells (data not shown), although, intracellular 3-AMP might involve cellular ATP level enhancement. Further studies are needed to elucidate the detailed biological significance of P-site inhibition of adenylate cyclase by 3-AMP, deoxyAMP, and deoxyAdo.

Acknowledgments The authors are grateful to Dr. M. Yasuda, Miss I. Sakae, and Mr. S. Itoh of Setsunan University for their technical assistance.

\section{REFERENCES}

1) Abbracchio M. P., Burnstock G., Jpn. J. Pharmacol., 78, 113-145 (1998).

2) Ralevic V., Burnstock G., Pharmacol. Rev., 50, $413-492$ (1998).

3) Johnson R. A., Yeung S. M., Stubner D., Bushfield M., Shoshani I., Mol. Pharmacol., 35, 681-688 (1989).

4) Fujimori H., Yasuda M., Pan-Hou H., Biol. Pharm. Bull., 25, 307 311 (2002).

5) Pilkis S. J., Claus T. H., El-Maghrabi M. R., Adv. Second Messenger Phosphoprotein Res., 22, 179-191 (1988).

6) Kawaguchi T., Veech R. L., Uyeda K., J. Biol. Chem., 276, 28554 28561 (2001).

7) Griffith D. A., Jarvis S. M., Biochim. Biophys. Acta, 1286, 153-181 (1996).

8) Fujimori H., Yamauchi M., Pan-Hou H., Chem. Express, 6, 715-718 (1991).

9) Fujimori H., Sasaki T., Hibi K., Senda M., Yoshioka M., J. Chromatogr., 528, 305-314 (1990).

10) Daly J. W., Adv. Cyclic Nucleotide Protein Phosphor. Res., 19, 29-46 (1985).

11) Jensen M. H., Jacobsen J. B., Acta Neurol. Scand., 76, 46-49 (1987).

12) Cadnapaphornchai P., Kellner D., Golembieski A., McDonald F. D., J. Pharmacol. Exp. Ther., 257, 774-780 (1991).

13) Dai X., Snow L. D., Int. J. Biochem., 23, $743-747$ (1991).

14) Nolan L. L., Kidder G. W., Biochem. Biophys. Res. Commun., 91, 253-262 (1979).

15) Morita Y., Nishida Y., Kamatani N., Miyamoto T., J. Allergy Clin. Immunol., 74, 707-712 (1984).

16) Marone G., Petracca R., Vigorita S., Casolarg V., Biochem. Pharmacol., 40, 1963-1973 (1990).

17) Nimit Y., Law J., Daly J. W., Biochem. Pharmacol., 31, 3279-3287 (1982).

18) Purich D. L., Fromm H. J., J. Biol. Chem., 246, 3456-3463 (1971).

19) Dunaway G. A., Jr., Weber G., Arch. Biochem. Biophys., 162, 620628 (1974).

20) Tanaka T., Harano Y., Sue F., Morimura H., J. Biochem. (Tokyo), 62, 71-91 (1967). 